\title{
It Takes Two to Say 'Hi': Evaluating College Teacher/Student Greetings in Kuwait
}

\author{
Nada A. Algharabali ${ }^{1, *}$, Rahima S. Akbar ${ }^{1} \&$ Hanan A. Taqi ${ }^{1}$ \\ ${ }^{1}$ The English Department, College of Basic Education, PAAET, Ardhiya, Kuwait \\ *Correspondence: The English Department, College of Basic Education, PAAET, Ardhiya, Kuwait. E-mail: \\ nads_50@hotmail.com
}

Received: November 7, 2019

Accepted: November 27, 2019 Online Published: December 18, 2019

doi:10.5430/wje.v9n6p15

URL: https://doi.org/10.5430/wje.v9n6p15

\begin{abstract}
As mundane and empty expressions as they may seem, greetings are necessary social behavior for the establishment and maintenance of interpersonal relationships no matter what setting they occur in or who the interlocutors are. We hypnotized that greeting behaviors may especially be beneficial with college students in academic contexts. With a socio-pragmatic perspective in mind, the present study investigates the importance of caring classroom behavior between college students and teachers. Quantitative analysis elicited from online questionnaires analyzed via SPSS in search of significance across variables, such as gender, age, and social status, showed both students and teachers strongly believe that exchanging greetings are a crucial part of classroom interaction as it leads to the overall success of the relationship between them. In an era of achievement-oriented education, students are expected to pave their way efficiently towards potential professional levels needed in the job market. It is therefore essential that research exploring, even the most mundane aspects of teacher/student interaction, helps in tailoring to the students' needs and interests.
\end{abstract}

Keywords: classroom interaction, college students and teachers, greetings and farewells, caring behavior

\section{Introduction}

Student academic incompetence at all levels of education has forever been one of the most widely investigated issues among educators. In a quest for constant educational reform, especially in fostering ways to help students thrive in their learning environment, comes a paradigm shift in pedagogical practices. Caring behaviors that are necessary for student achievement are one aspect of these practices, which when acknowledged by teachers and school and college administrators, can help break down barriers between teachers and students (Graza et al., 2010).

If teachers establish positive engagements as well as productive relationships with their students, the students, in turn, are likely to become more responsive and motivated to succeed (King and Chan, 2011). This positive academic climate is especially necessary at college level where students are immediately aware of the popular teachers who like working with students as opposed to the unpopular, uncaring and disengaged type of teachers who usually have a lower rate of student attendance in their classes as a result (Graza et al., 2010; and Wentzel, 1997).

One of the most effective ways in which a teacher can build positivity is to know their students. Greeting them when entering the classroom is definitely the first step to knowing them. According to Daniels (2011), when teachers greet students, they appear to be more approachable. Also, this behavior shows students that the teacher is interested in them as individuals and not simply in the content being presented in class. Very often, this as a result, will lead to students behaving in a more positive way in class (Daniels, 2011).

\section{A Socio-pragmatic Overview on Greetings}

From a socio-pragmatic perspective, greetings mostly cultivate their meaning and importance from the culture they come from (Holmes, 1992). Moreover, by and large, research involving the phenomenon of greetings postulates that both the content and function of greeting formulas are culture-specific (for a review, see Goffman, 1971; Gudykunst and Kim, 2003; and Furguson, 1967). Holmes (1992) has argued that people greet one another in order to make a 
conscious effort to acknowledge each other's presence. Researchers also concede that the type of greeting and its familiarity intensity (as opposed to distant greeting) depends on numerous social factors between speaker and hearer, such as: social status, gender, age, formality, social distance and context (see Mey, 2001; Goffman, 1967; Brown and Levinson, 1987; and Leech, 1983). Even though very often greetings may seem semantically empty on a superficial level, they do have pragmatic value since they fulfill part of a social ritual when people meet (Kuiper and Flindall, 2000). This is constantly reinforced when silence replaces a greeting leading to possible threatened interpersonal relations between speaker and hearer, which in turn have a negative pragmatic value.

According to Goffman (1971), therefore, greeting exchanges are characterized as access rituals consisting of two types: 'passing greetings' and 'engaging greetings', both of which function as a switch that opens or closes relations between speaker and hearer (1971: 79). In his work on 'face-supportive acts', drawn from Austin's (1962) speech act theory, Goffman (1967) maintains that greetings are generally regarded as positive politeness devices which often express solidarity and friendliness, even though most of the time greeting exchanges may seem meaningless or force-of-habit type of gestures. Additionally, Akindele (2007) examines greeting expressions by the Lesotho people of South Africa and argues that these expressions are very important strategies used to negotiate and establish control over social identity and social relationships between hearer and speaker during interaction. Other types of greetings can be categorized, according to Dzameshie (2002), into: 1) 'Time-of-day' greetings, and 2) 'How-are-you' greetings, which literally aim at enquiring about the other's health. While Akindele (2007), points to the valedictory greetings, which are reserved for 'ways of parting/ leave taking'.

Kuiper and Flindall (2000), who looked at social rituals and small talk at checkout counters in supermarkets, point out that in certain cultures service encounters between employee and customer, such as greetings, tend to be insincere and possibly artificial. This is mainly because the management expects employees to be polite and welcoming to customers, and therefore, a greeting expression in this case is mandatory as opposed to a choice reflecting common courtesy.

A key aspect of greetings worth highlighting here is that there are certain settings or domains where the social status differences between speaker and hearer allow the party in a position of power to establish greeting behaviors, since it is they, according to Fairclough (1989), who decide what is appropriate during interaction. One example of such a domain are academic settings, such as schools and colleges, where it is usually the teacher who is in a superior position and thus determines the greeting pattern between them and students. The limited literature that investigates greeting behavior between teachers and students in academic settings tend to focus on the greeting phenomenon as a caring behavior and pedagogic motivator (see, for example Philipp and Thanheiser, 2010; Daniels, 2011; Gillen et al., 2011; and Williams and Williams, 2011).

Typically, much of the research on teachers showing students they care revolves around various strategies of caring behavior but generally fails to focus on the necessity of teachers greeting students as a caring behavior. Philipp and Thanheiser (2010), for example, highlight an important notion, namely that caring for students alone is not enough, students need to sense that their teacher actually cares about them through practical behavior. This involves talking with them about issues other than the subject being taught, like their hobbies, for example. They argue that not many teachers are capable of such caring engagements because they may be 'threatened by the idea of talking one-on-one with a student', which may cause 'teachers to feel vulnerable' (2010: 12). One could argue whether the teachers who avoid greeting students are in fact trying to prevent an increased chance of one-on-one interaction with students. Other researched caring strategies that also fail to acknowledge greeting students, involves positively affirming students' efforts and talents (see Lumpkin, 2007). Lumpkin adds that teachers can be caring towards students by enhancing their pedagogic approaches, such as using multiple instructional methods to increase students' learning opportunities. And finally, King and Chan (2011) conducted a study examining students' and teachers' perceptions on how a teachers' caring behaviors promote students' academic achievements, but they do not specifically examine greetings as a caring behavior, but rather simply as a marginal part of mundane daily classroom interaction.

Clearly, therefore, a relatively limited amount of research focuses on greeting rituals between teachers and students in general, let alone at college level. For example, Allday and Pakurar (2007) examined the effect of teachers' greetings on students in middle school. They found out that teachers' greetings improved students' on-task behavior in the classroom. In addition, Almoaily (2018) conducted a study, which looks at greetings as a politeness strategy in EFL distance learning. He concluded that Saudi college students are unaware of appropriate formal greetings use in computer-mediated communication with their graduation project supervisors abroad (also see a similar study by Huang, 2016). Other greeting studies carried out in the Middle East region have mainly focused on examining greeting rituals in general everyday settings as a routine cultural phenomenon but not in academic contexts (see for 
example, Rabee and Al-Haq, 2017; and Rababa'h and Malkawi, 2012).

Considering the notable research gap in the Middle East region concerning teacher/student greeting behaviors in academic settings and their importance, we believe that there is a great necessity for this type of interaction to be investigated at a wider quantitative scale. The present study will therefore undoubtedly introduce insights in this area of study and the cultural region afore mentioned. Moreover, one of the main incentives behind the present study is the fact that the current teacher evaluation survey at the College of Basic Education (CBE), Kuwait, which is answered by students towards the second half of every academic semester, does not address the concept of greetings between teachers and students in classroom interaction. This marginalizes the importance of greetings and the role these verbal exchanges may play in encouraging positive student/teacher relationships, and fostering academic success. Therefore, in this research paper, we hope to shed light on the following research queries: 1) Are students and teachers aware of the importance of greetings as part of classroom interaction? And if so, which type and manner of greetings do teachers and students seem to favor? 2) Do students and teachers believe that greetings should be limited to in-college interaction? 3) Are farewells important to classroom interaction? 4) Should teachers engage in small talk with students besides greeting them?

\section{Methods}

\subsection{Participants}

This study aims to investigate the importance of greeting and farewell expressions as caring behaviors that take place during daily interaction between college students and teachers. The sample of student participants in this study was deliberately chosen to represent a specific age group (18 - 24 years). During this age period, students can still recall their high school years while in the process of being college students (or still recall their college years, if they have just graduated) and they are therefore able to draw comparatives between daily interactional patterns they have experienced in both worlds.

The first group of participants who took part in the present study consisted of 298 students, 170 female and 128 male. The students, who come from different public and private universities and colleges in Kuwait were divided between $50 \%$ : $4^{\text {th }}$-year college students, $29 \%: 3^{\text {rd }}$-year students, and 21\%: graduates. The second group of participants in the present study consists of 45 teachers, 27 female and 18 male all from the College of Basic Education (CBE). Their ages ranged between $30-60+$ years old (50\%: $30-40$ years, 27\%: $41-50$, and 20\%: $51-60)$. All the teachers are $\mathrm{PhD}$ holders and come from different disciplines, such as sociolinguistics, music, psychology, education, and so on. A final point worth mentioning is that the quantitative data was cross-examined along several variables, namely: gender, age and social status, to obtain clearer insights to whether the importance of greetings between students and teachers was viewed differently by younger or older teachers, by different college year students, and by male or female students and teachers based on their social backgrounds.

\subsection{Study Design and Data}

Given that a quantitative approach usually provides numeric descriptions of opinions of a teacher/student population by looking at a sample of that population (Creswell, 2009), the research design utilized for this study encompasses a quantitative survey method in the form of two questionnaires. The questionnaires are similar in form and content and both consist of 11 questions targeting the 4 focal points of enquiry mentioned earlier. One version was given to students and another to teachers. Both questionnaires were designed to gather insights and perceptions on the importance of the basic functions of greetings in daily interaction between college students and their teachers in Kuwait. For the sake of convenience and anonymity, the questionnaires were conducted online. The data from the questionnaires were analyzed via SPSS showing descriptive statistics across the three variables mentioned above.

Additionally, in order to enrich the quantitative data gathered from the questionnaires, a small-scale interview with a limited number of students was carried out in the form of classroom group-discussion. Since the participating students will become prospective teachers upon graduating, it was very convenient to put forth the following topic of discussion in class: "Student and teacher routine interaction: Greetings" as a topic of discussion in class. The discussion was conducted on one class only. The class consists of 25 , third-year female CBE students attending a course in sociolinguistics. Naturally, this would give a topic on greetings (a sociolinguistic subject matter, which commonly occurs in verbal exchanges in social settings) a relevant vantage point. These students, who already participated in answering the questionnaire, were asked if they cared to elaborate on their answers. They were given a choice to leave the classroom if they did not wish to take part in the discussion - however, none actually left. One of the researchers (also the teacher of the class) took thorough shorthand notes on students' opinions. It was hoped 
that a group discussion would encourage students to speak more freely about a topic that seemed to be of importance to them.

Moreover, seen that students apparently appear to find it easier to air out their views verbally as opposed to expressing themselves painstakingly through writing, conducting a classroom group-discussion seemed like a good strategy to gain more insight into the focal points of investigation. A point of ethical importance worth mentioning here is that the students were informed by the class teacher before their feedback and views may be used for research purposes.

\section{Results}

\subsection{Quantitative Data}

The data obtained from the online questionnaire was statistically analyzed in SPSS in search for mean, frequency and significance of the independent variables. Most questions had a comment box where teachers and students could add a comment. The comments are displayed below with the analysis of the questions. The most important finding was that no independent variable had a significant effect on the results. Moreover, the results significantly show that students are more interested in greetings, as they provided more elaborate comments and explained how they feel in detail.

The first question in the questionnaire inquired about the importance of greetings. While $90 \%$ of the students found greetings to be necessary, $86 \%$ of the teachers found them necessary. The reasons given (by students only) of the importance of greetings were as follows (the reasons are arranged in chronological order based on popularity):

- Feeling comfortable and welcome in class.

- Spreading positive energy and vibes.

- Strengthening the teacher-student relationship and feeling a friendly atmosphere.

- Feeling respected.

- Breaking the ice and less class tension.

- Indicating the beginning of class.

- It's good manners.

When asked what type of greetings do students prefer, $50.3 \%$ of the students preferred those related to the time of day "Good morning", yet, $60 \%$ of teachers preferred the religious "peace be upon you" (alsalamu alaikum). $27.5 \%$ of the students chose the religious greeting and $22.2 \%$ for casual "hi" and "hello". $20 \%$ of the teachers chose the time of day greeting and $20 \%$ the casual one. Figure 1 below, reflects the students' preference of being greeted by teachers.

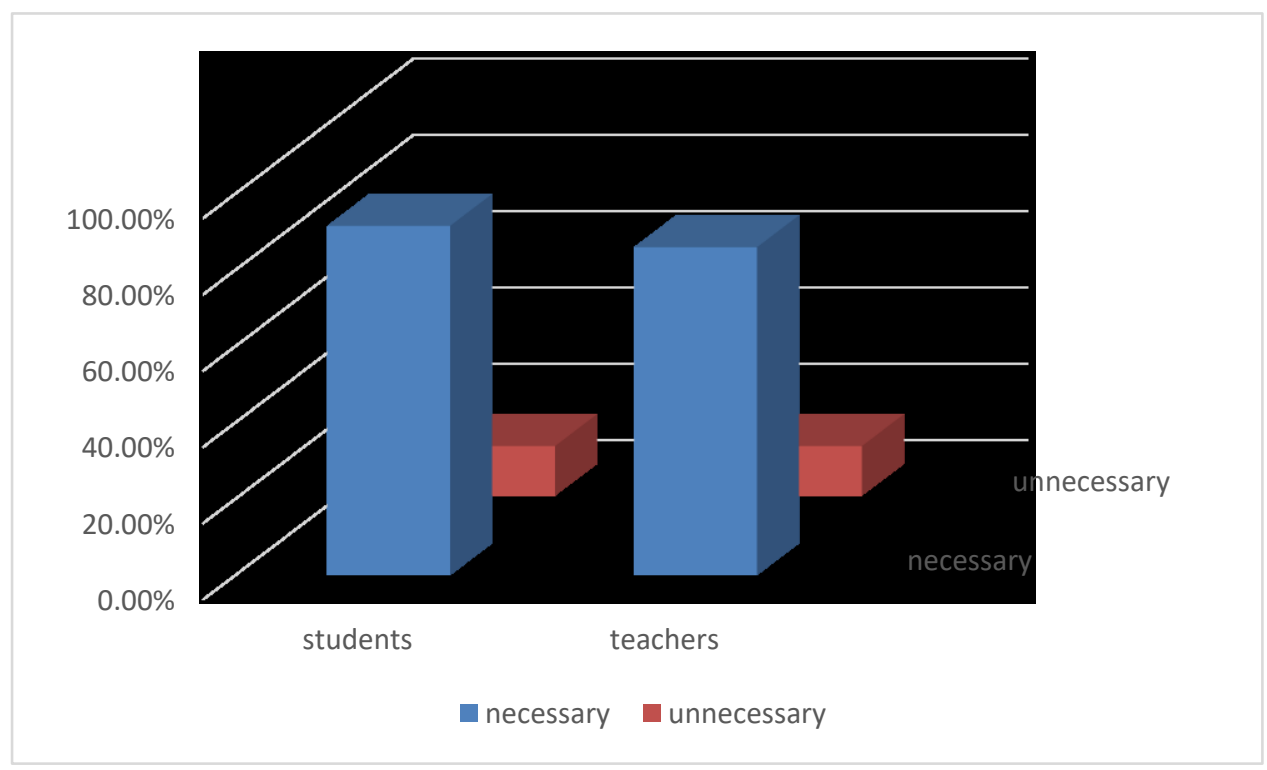

Figure 1. Should Teachers Greet Students? 
The 'time of day' type of greeting was preferred by students and some teachers, mostly because they feel it is formal, but at the same time friendly. Some students believe there is more positivity in time of day greetings. A few teachers commented that they use time of day greetings to break the ice, as it is less formal. In addition, some students stated that if the class is taught in English, the religious greeting would not be appropriate; hence, the formal option would be time of day greeting. Many students reflected their belief that religious greetings should not be used as it assumes that the students all come from the same religious and ethnic backgrounds. On the other hand, students who believe religious greetings are more appropriate defended their belief by stating it has a beautiful meaning, and it is Islamic. However, the majority of students stated that they would not mind any type of greeting as long as it conveys respect and friendliness.

The third question addressed the method of greeting. $50 \%$ of the participating students and $40 \%$ of the participating teachers preferred a greeting with a smile. $47 \%$ of students and $33.3 \%$ of teachers preferred greetings with small talk. $20 \%$ of the teachers preferred greeting with a straight face.

The fourth question inquired about the placement of greeting. The participants were given two choices: Teachers greeting students as they walk into class or greeting students upon standing in front of them in class. Unlike teachers, the majority of students pointed out that they prefer to be greeted while walking into the room $(40 \%$ and $60 \%$, respectively). Only students offered their comments in this respect. Most comments indicated that the students prefer to be greeted as the teachers walk into class because it indicates that class has started and students should be ready. Some students believe that standing in front of the class and then greeting students is more serious, formal and professional.

When students were asked if they felt comfortable when greeted, $69 \%$ said they do all the time, and $25 \%$ replied sometimes. Yet, $4.7 \%$ and $1.4 \%$ replied with rarely and not at all (consecutively). This question aimed at understanding not only the importance of greetings but also its effect as a comforting and caring factor.

Do the students greet the teachers back? Both teachers' and students' responses to that question were surprisingly different. Figure 2 below, reflects both students' and teachers' answers, which show that students believe they reply to greetings most of the time. All the comments from the teachers reflected the importance of replying as an indicator of attentiveness, friendliness, and respect. However, a few students stated they reply because they got used to it in school, especially the reply to religious greetings (which is a given in Muslim societies). Additionally, only a few students rarely reply because they feel embarrassed. The majority of students stated that they reply to greetings out of respect and sense of duty.

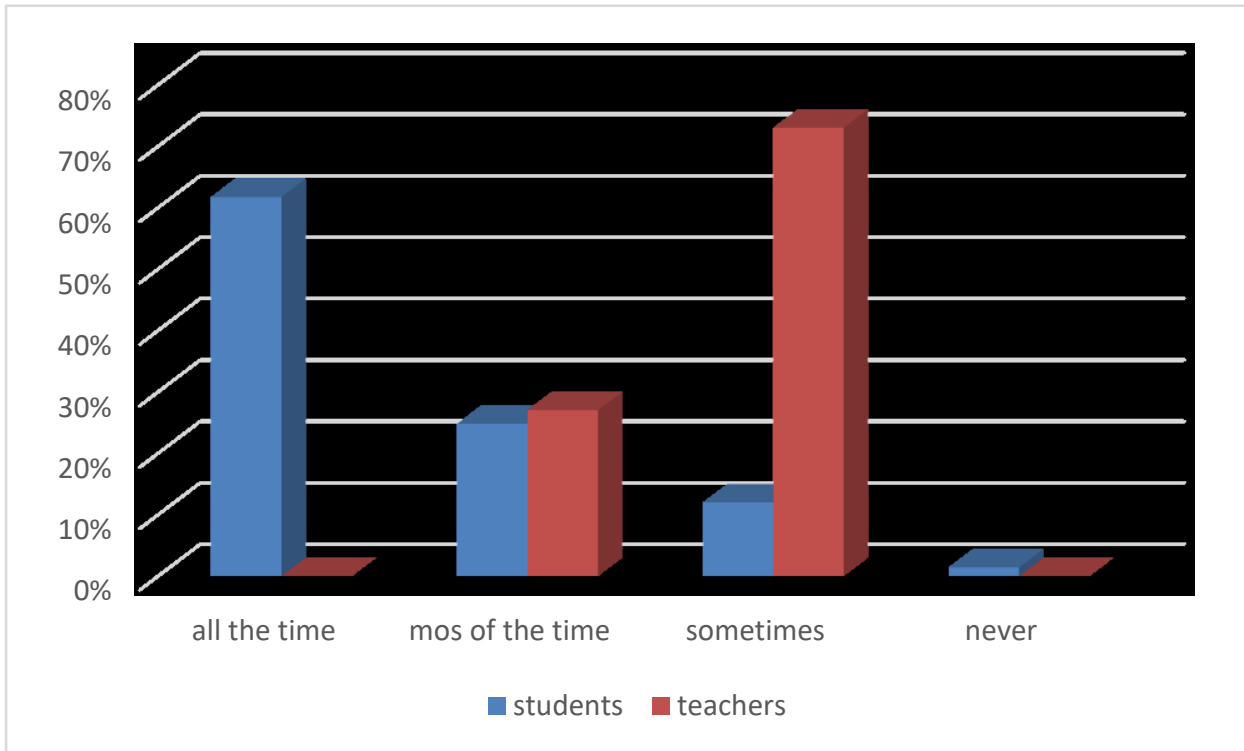

Figure 2. Do Students Greet Teachers Back?

From the data obtained, it is clear that the students would not necessarily greet teachers off campus premises. Actually, $8.7 \%$ would never greet a teacher if seen in public! Teachers, however, would mostly greet their students (53.3\%). Figure 3 below, reflects the probability of greetings to occur between teachers and students off campus. 


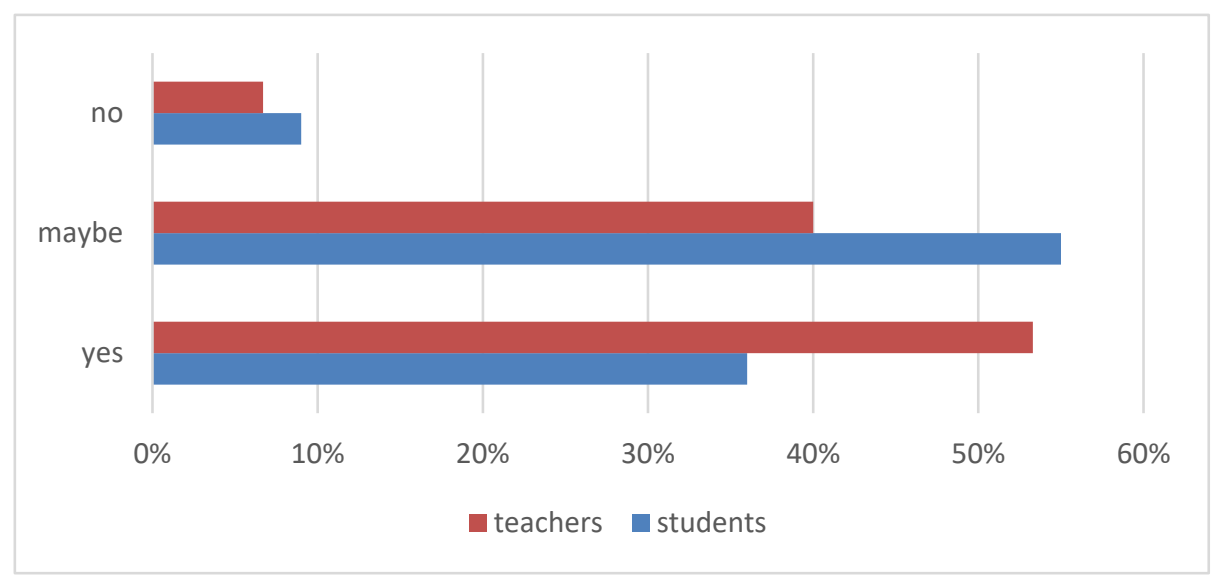

Figure 3. Would You Greet Your Teacher/Student in Public?

The teachers commented in this respect that sometimes it depends on a student's body language. One teacher stated that she would greet her students but only "if she/he greets me first". The students who do greet are those who do not feel it is embarrassing. Yet, some students think it depends on their feelings towards the teacher; and whether their teacher is usually friendly at college, and the depth of the relationship between student and teacher. Surprisingly, many students stated they would be reluctant because they believe teachers do not accept such behavior out of college context!

Should the question: "Is it necessary for teachers to greet students?" be included in the teacher's evaluation? 55.7\% of the students stated "yes", $27.5 \%$ said "maybe", and 16.8\% said "no". In this respect, many students commented that that they believe that the act of greeting is a very important criterion of evaluation, as it is part of teaching and reflects respect. Nonetheless, some students believed that the aim of the evaluation usually addresses the teacher's ability to teach not socialize.

The teachers, on the other hand, did not seem to agree with the students. $40 \%$ of the teachers were unsure about including greetings as a criterion in the evaluation, while $33.3 \%$ believed it should not be part of the evaluation, altogether. One of the teachers commented: "I think it should not be. 'Treating students with respect' is already available as a criterion, which I believe implies greeting them, too".

Wishing students farewell seems to be more important for students than teachers, too. While $80 \%$ of the students stated that farewells are necessary, $73.3 \%$ of the teachers agreed. Nonetheless, none of the participants found wishing students farewell unnecessary. Some teachers felt that wishing students farewell will keep the positivity. One teacher added "it would be awkward and abrupt if I left without any sort of parting expression". Most students agreed that farewells are important because they emphasize good manners. In addition, the participating students expressed their belief that teachers bidding students farewell indicates end of class and it shows that the teacher cares. Most students added the words "it would be nice" in their comments, which reflects the degree of preference of a farewell as a parting gesture.

To both students and teachers, greetings seem to be very important. In fact, it is the most important part of social interaction according to $44.3 \%$ of students and $45.2 \%$ of teachers. Teachers chose farewell as the second most important part of social interaction, commenting that greetings and farewells signal the beginning and end of lectures. Students, however, preferred small talk to farewells (32.3\% and 23\% successively). Most students stated that they like to create a bond with their teachers, as it makes learning fun. However, some students are reluctant when it comes to small talk as they fear small talk might lead to disrespect. Table 1 below, reflects the importance of social interaction gestures in the point of view of teachers and students. 
Table 1. The Importance of Social Interaction Behaviors

\begin{tabular}{ccc}
\hline & Teachers & Students \\
\hline Greeting & $45.2 \%$ & $44.3 \%$ \\
Farewell & $32.3 \%$ & $23 \%$ \\
Small talk & $22.5 \%$ & $32.3 \%$ \\
Nothing at all & $0 \%$ & $0.4 \%$ \\
\hline
\end{tabular}

\subsection{The Interview: Classroom Group-discussion}

The students started the discussion by pointing out the first important and obvious difference between high school and college: that teachers greet college students when coming into class and sometimes even bid them farewell upon leaving class. One student expressed the following:

"When you're ignored by teachers for 4 years in high school only to be greeted by teachers at college, it feels like a shock, because you go from being invisible to becoming a visible individual."

Another student mentioned that she immediately felt mature upon joining college because "teachers actually make eye contact and say 'Hi'” as she put it.

But the discussion soon changed direction when other students joined in and seemed to disagree with what was being said by pointing out that not all teachers greet students when coming into class and according to them:

"Many don't even bother to say 'good morning' and prefer to come silently and abruptly start the lecture by explaining the designated part of the curriculum on a given day".

Several students seemed to agree adding that some teachers would actually say "Hi" but in a very cold and uncaring manner making the whole gesture appear pointless.

The classroom then erupted into a discussion about the importance of teachers making an effort to "break the ice" and welcoming students by greeting them as a gesture of caring behavior, which according to students ultimately encourages a positive and healthy classroom environment. As a result, they believe that this, increases student motivation for the subject matter, improves academic performance, and leads to higher success rates.

A few students added that sometimes the 'mood' of the teacher explains "why they don't greet us, especially if for example, we've done poorly in the midterm exam." The discussion was brought to an end when most students appeared to generally point out that, "greeting a person is a 'must' because it's part of our Islamic culture, which encourages people to greet each other even if they don't know one another." They also added: "greeting people upon entering a place is naturally understood as part of social etiquette".

\section{Discussion}

The present study looks into the importance of greetings within the context of academia from both the students' and teachers' perspective. Participants were asked about greetings patterns in two different settings: in-class greeting behavior and greetings that took place off-campus in public settings.

The study's results indicate that both teachers and students appreciate the role of greetings as part of classroom interaction. Nevertheless, the findings suggest a number of contradictory views between students and teachers in terms of greeting details, including the preferred greeting type and greeting behaviors, all of which are clarified further below.

As for the utilized expression or formula of certain greeting types, it appears that students would usually prefer time of day greetings such as "Good morning" and "Good afternoon", especially when they are conveyed with a smile as the teacher walks in to the classroom. For students, time of day type of greetings, which are usually somewhat formal or as Goffman (1967) refers to as 'force of habit' greetings, are regarded as informal or friendly because of the manner of which they are conveyed. Teachers, on the other hand, find "assalamu alaikum" meaning: "peace be upon you' to be the most appropriate greeting type during classroom interaction. Students tend to disagree with teachers since they perceive this religious greeting as being too formal and inappropriate given that classroom settings are mostly in English. Although, some feel that this expression has its own cultural and religious charisma in other contexts.

The findings in the present study also seem to highlight the degree of sincerity in a greeting manifested through nonverbal facial expressions, such as smiling while saying "hi", a point which was previously discussed (see Kuiper 
and Findall, 2000). While both the teachers and students who participated in this study agree that a greeting accompanied with a smile is quite important. Moreover, the students have added that some 'small talk' following a greeting is even more favorable. It seems therefore that the smile that accompanies a greeting is yet another simple gesture which projects the greeter's sincerity - an act, in which a speaker has to engage to maintain the hearer's feelings or what Goffman (1967) aptly refers to as: 'face-supportive acts'.

It is quite noticeable from students' opinions that they strive to create familiarity with their teachers and thus moving away from formal and more stoic patterns of interaction in class. This is conveyed not only by preferring less formal types of greetings and engaging in small talk with their teachers, but also by favoring that their teachers greet them in an informal manner while walking into the classroom as opposed to standing in front of the class and formally commencing the class session with a greeting. Although this pursuit for familiarity does not seem to surpass the college context, as students do appear reluctant to greet their teachers when encountering them in various off-campus public spaces. It is almost as though the college setting allows students and teachers to attempt to soften the boundaries of power or mitigate the differences in social status between teacher and student through simple everyday gestures such as greeting one another. As Fairclough (1989) noted, it is usually the person of higher social status or the one in a position of power that controls the contributions during interaction. In this case, therefore, it is the teacher who initiates the greeting and the manner in which it is delivered.

However, it has to be borne in mind that teachers would like to see more interaction on the part of the students as they seem to believe that not enough students appear to care enough to answer their teachers' greetings. Although, the students beg to differ on this point and they find that greetings are of such importance that they should be included as a criterion in the biannual teacher evaluations that are set up for the benefit of the students. On the other hand, teachers believe that the interactional behavior of greeting (or not greeting and therefore silence) should be left to a teacher's discretion and should not feel like an obligation, especially if it is to come across as sincere and caring. In addition to that, despite the fact that greetings make a teacher seem academically professional, not all teachers believe it is necessary classroom behavior; perhaps fearing it may invite more interaction than a simple greeting, a point suggested earlier by Philipp and Thanheiser (2010). In fact, this coincides with King and Chan (2011) who fell short of mentioning greetings as an interactional, caring behavior in a major research that addresses caring behavior by teachers towards students. The idea that greetings are seen as an interactional behavior which shows care and respect is of key importance since, as argued earlier, it is bound to increase students' motivation and attention in class and ultimately improve their academic performance. Promoting student academic achievement is every educator's main priority (see Figure 1, also see Daniels, 2011; Gillen et al., 2011; and Williams and Williams, 2011).

Last but not least, according to the results in the present study, if greetings are important friendly behaviors that mark the beginning of a classroom session, then 'farewells' are equally as important according to testaments by both students and teachers. Teachers find a farewell expression to be an important positive interactional behavior, which helps bring the classroom session to a gradual end rather than an abrupt one. Additionally, students feel that the use of farewell expressions reflects good manners, respect and a caring parting gesture on the part of the teacher, a vital point which was identified earlier by Graza et al. (2010). Another point that coincides with what Daniels (2011) argued about the necessity for teachers to show caring behavior, was what students believe is the outcome of teachers caring about them. According to comments shared by students during the interview: "teachers who show concern towards us will undoubtedly increase our interest in the subject'. Similar comments taken from the survey indicate that when teachers show concern, students feel: 'more motivated' and that 'it breaks the ice in class'. In fact, all participants were asked to rank classroom interaction behaviors based on order of importance: 'greetings' (chosen at the top of the list by both poles), were followed by 'farewells' for teachers and 'small talk' and then 'farewells' for students. Interestingly then, the question that imposes itself at this point is: How can simple gestures, such as teachers saying, "Good morning" and "Bye, see you next time" to students play such an important role in teacher/student interaction as well as have such an impact on building a positive relationship between them? And more importantly how do these verbal gestures ultimately affect students' overall academic achievements? Figure 1 below, presents an overview of the fundamental role that greetings play in classroom interaction. The phrases in this Figure are quotes taken from the responses contributed by students in the comment sections of the students' questionnaires (note: only the most common responses are utilized). 


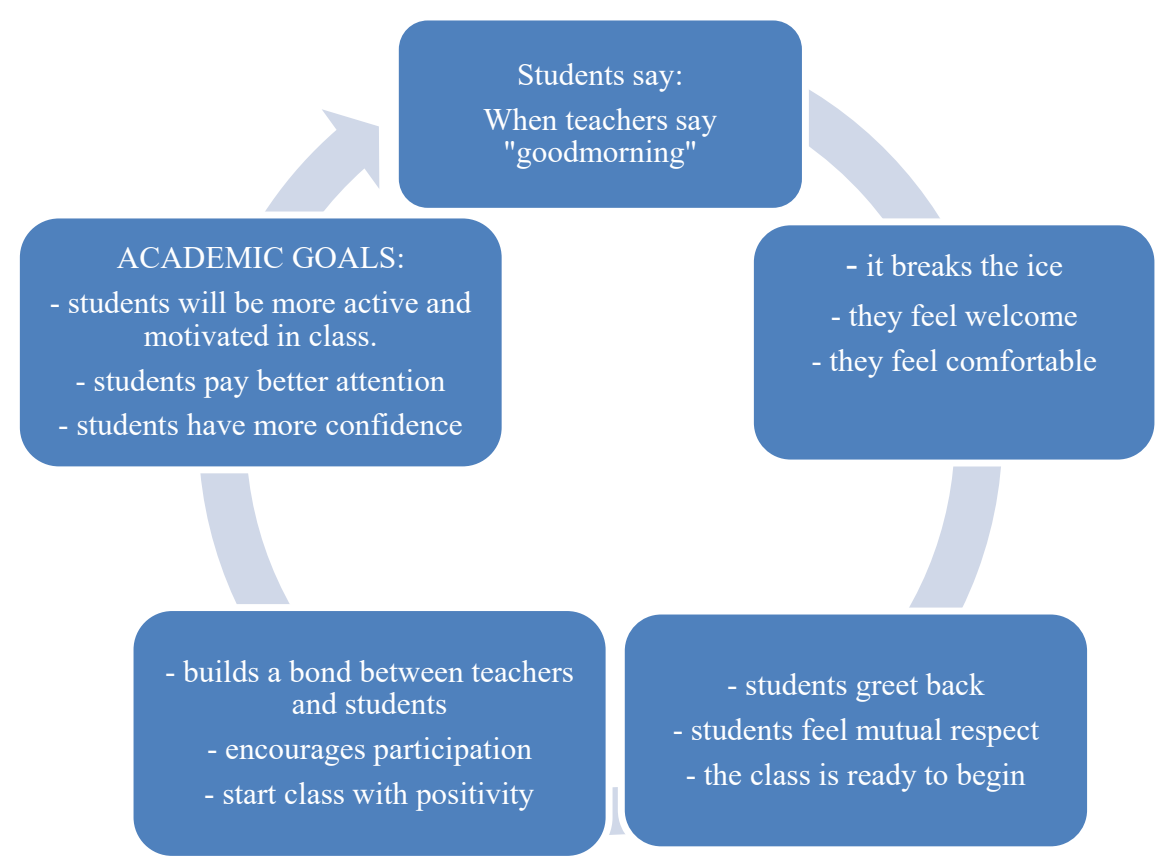

Figure 1. The Cycle of Greetings: Affect, Reactions and Outcomes

\section{Conclusion}

The present exploratory study raises a number of fundamental insights regarding classroom interaction between students and teachers. If according to the results presented here: greeting and parting exchanges help foster social competency between students and teachers and promote student academic achievement, then could it also mean that the absence of these exchanges or the presence of silence instead imply more pronounced power boundaries that render students unable to approach their teachers? An important question indeed and one that encourages further in-depth research albeit covering a wider teacher/student sample in more diverse settings. To sum up then, the present study presented a clear perspective on the importance of simple caring interactional behaviors, such as greetings and farewells between teachers and students across variables, such as age and gender - while the social status variable was not noted to have much significance in the case of this study. Our initial and basically exploratory investigation and significant findings regarding these interactional patterns in this context clearly call for similar studies in this area to be carried out.

A limitation worth mentioning was the lack of access to teachers' insights via face-to-face interviews. Not being able to verify the teachers' views meant that our results could, to some extent, be biased towards students' views over teachers' perceptions. Additionally, since many students highlighted the difference between public schools and colleges in Kuwait, it may well be worthwhile extending the scope of the present study to include public schools in the future. By doing so, we are bound to widen the circle of awareness to the importance of creating a caring and positive teaching-learning atmosphere in various other academic settings.

\section{References}

Akindele, D. F. (2007). Lumela/Lumela: A socio-pragmatic analysis of Sesotho greetings. Nordic Journal of African Studies, 16(1).

Allday, R. A., \& Pakurar, K. (2007). Effects of teacher greetings on student on-task behavior. Journal of applied behavior analysis, 40(2), 317-320. https://doi.org/10.1901/jaba.2007.86-06

Almoaily, M. (2018). Greetings as a Politeness Strategy in EFL Distance Learning Students' Official Emails. Linguistics and Literature Studies, 6(6), 259-266. https://doi.org/10.13189/1ls.2018.060601

Austin, J. L. (1975). How to do things with words. Oxford University Press: braska-Lincoln. https://doi.org/10.1093/acprof:oso/9780198245537.001.0001

Brown, P., Levinson, S. C., \& Levinson, S. C. (1987). Politeness: Some universals in language usage (4th ed.). 
Cambridge University Press. https://doi.org/10.1017/CBO9780511813085

Creswel, J. W. (2009). Research design: Qualitative, quantitative, and mixed methods approaches. Los angeles: University of $\mathrm{Ne}$.

Daniels, E. (2011). Creating motivating learning environments: Teachers matter: Teachers can influence students' motivation to achieve in school. Middle School Journal, 43(2), 32-37. https://doi.org/10.1080/00940771.2011.11461799

Dzameshie, A. K. (2002). The forms, functions and social value of greetings among the Ewes. New directions in Ghanaian linguistics, 381-408.

Fairclough, N. (2001). Language and power. Pearson Education.

Ferguson, C. A. (1976). The structure and use of politeness formulas. Language in society, 5(2), 137-151. https://doi.org/10.1017/S0047404500006989

Garza, R., Ryser, G., \& Lee, K. (2009). Illuminating adolescent voices: Identifying high school students' perceptions of teacher caring. Academic Leadership: The Online Journal, 7(4), 18.

Gillen, A., Wright, A., \& Spink, L. (2011). Student perceptions of a positive climate for learning: a case study. Educational Psychology in Practice, 27(1), 65-82. https://doi.org/10.1080/02667363.2011.549355

Goffman, E. (1967). Interaction ritual: essays on face-to-face behavior. New York: Anchor Books

Goffman, E. (2009). Relations in public. Transaction Publishers.

Gudykunst, W. B., \& Young, Y. Kim. (2003). Communicating with Strangers: An Approach to Inter-cultural Communication. Boston: McGraw Hill.

Holmes, J., \& Wilson, N. (2017). An introduction to sociolinguistics. Routledge. https://doi.org/10.4324/9781315728438

Huang, H. C. (2016). Openings and closings in intercultural email communication: A case study of Taiwanese, Japanese, and Italian students. In email discourse among Chinese using English as a lingua franca, 185-204. Springer, Singapore. https://doi.org/10.1007/978-981-287-888-5_9

King, P. C., \& Chan, T. C. (2011). Teachers' and Students' Perceptions on Teachers' Caring Behaviors. Online Submission.

Kuiper, K., \& Flindall, M. (2000). Social rituals, formulaic speech and small talk at the supermarket checkout. In Small talk, (Ed.), by Justine Coupland, 183-207.

Lumpkin, A. (2007). Caring teachers the key to student learning. Kappa Delta Pi Record, 43(4), 158-160. https://doi.org/10.1080/00228958.2007.10516474

Mey, J. L., \& Xu, C. (2001). Pragmatics: an introduction. Malden: Blackwell Publishing.

Philipp, R. A., \& Thanheiser, E. (2010). Showing Your Students You Care: Seeing the Individual Trees in the Classroom Forest. New England Mathematics Journal, 42, 8-17.

Rababah, M. A., \& Malkawi, N. A. A. (2012). The linguistic etiquette of greeting and leave-taking in Jordanian Arabic. European Scientific Journal, 8(18).

Rabee, R. S., \& Al-Haq, F. A. A. (2017). The Speech Act of Greetings in Selected Verses of the Glorious Qur'an: A Socio-Pragmatic Study. US-China Foreign Language, 15(2), 91-110. https://doi.org/10.17265/1539-8080/2017.02.004

Thomas, J. (1983). Cross-cultural pragmatic failure. Applied linguistics, 4(2), 91-112. https://doi.org/10.1093/applin/4.2.91

Wentzel, K. R. (1997). Student motivation in middle school: The role of perceived pedagogical caring. Journal of educational psychology, 89(3), 411. https://doi.org/10.1037/0022-0663.89.3.411

Williams, K. C., \& Williams, C. C. (2011). Five key ingredients for improving student motivation. Research in Higher Education Journal, 12, 1. 


\section{Index 1:}

\section{Student's Questionnaire}

Please answer the following questions as part of a research investigation into the nature of daily interaction; more specifically 'greetings'. Your feedback could help us find ways to help improve teacher/student interaction.

* Gender: a. Female b. Male

* Nationality:

* Age Group: Less than 20-20-25 25-30

1) Do you think your teacher should greet students as $s /$ he enters class ? Why?
a. Very necessary
b. Necessary
c. Not so necessary
d. Unnecessary

* Why?

2) Which greeting type do you think your teacher should use upon entering class? Why?
a. Religious (Al Salamu Alaikum)
b. Time-of-Day (Good morning)
c. Friendly/casual (Hi, Hello)
d. Non-verbal (A hand wave)

* Why?

3) Do you prefer your teacher to use ?
a. Short simple greetings (e.g. Hi)
b. Greetings with small talk (e.g. Hi. How are you all)
c. A greeting with a smile
d. A greeting with a straight face

4) Do you prefer your teacher to greet students ?
a. As s/he walks into the classroom
b. Once $\mathrm{s} /$ he is standing in front of the class

5) I feel comfortable in class after I'm greeted by my teacher?
a. All the time
b. Sometimes
c. Rarely
d. Not at all

Do you greet your teacher back after s/he has greeted the class upon entering ? Why?
a. All the time
b. Most of the time
c. Sometimes
d. Never

* Why?

6) What type of greeting would you prefer to use when you visit your teacher's office for an enquiry ?
a. A formal greeting (Good morning)
b. An informal greeting (Hi)
c. No greeting

7) Would you greet your teacher if you saw him/her out in public (e.g. at the mall)? Why?
a. Yes
b. No
* Why?

8) Do you think 'teachers greeting students' could be a category that should be included in the college's teacher evaluations? Why?
a. Yes
b. No

* Why?

9) Do you think your teacher should wish the class farewell (e.g. Bye, Have a nice weekend) as s/he leaves the classroom? Why?
a. Very necessary
b. Necessary 

c. Not so necessary
d. Unnecessary

* Why?

10) Which of the following teacher/student classroom interaction type would you recommend? Why? (You may choose more than one answer)
a. Greeting
b. Farewell
c. Small talk
d. Nothing at all
* Why?

Index 2:

\section{Teacher's Questionnaire}

Please answer the following questions as part of a research investigation into the nature of daily interaction; more specifically 'greetings'. Your feedback could help us find ways to help improve teacher/student interaction.

* Gender: a. Female b. Male

* Nationality:

* Age Group: $30-40 \quad 40-50 \quad 50-60+$

1) Do you think greeting students as you enter class is
a. Very necessary
b. Necessary
c. Not so necessary
d. Unnecessary

2) Which greeting type do you prefer using with your students upon entering class? Why?
a. Religious (Al Salamu Alaikum)
b. Time-of-Day (Good morning)
c. Friendly/casual (Hi, Hello)
d. Non-verbal (a hand wave)

* Why ?

3) Do you prefer to use
a. Short simple greetings (e.g. Hi)
b. Greetings with small talk (e.g. Hi. How are you all)
c. A greeting with a smile
d. A greeting with a straight face

4). Do you prefer to greet students $?$
a. As you walk into the classroom
b. Once you're standing in front of your class

5) How do you feel when the students greet you back as you enter class?
a. Very happy
b. Happy
c. Indifferent
d. None of the above

6) How many students greet you back after you have greeted them upon entering class $?$
a. All
b. Many
c. Some
d. None

7) My choice of greeting depends on (You may choose more than one answer)
a. My mood
b. The weather (e.g. when it's very hot outside)
c. Class interaction (positive vs. negative)
d. The class's general vibe (a diligent and attentive vs. difficult class)
e. My way of greeting doesn't change

f. Other (please specify) 
8) Would you greet a student if you saw him/her out in public (e.g. at the mall)? Why?
a. Yes
b. No (Why?)

9) Do you think 'teachers greeting students' could be a category that should be included in the college's teacher evaluations? Why?
a. Yes
b. No
c. Why?

10) Do you think wishing students farewell (e.g. Bye. Have a nice weekend) as you leave the classroom is ? Why?
a. Very necessary
b. Necessary
c. Not so necessary
d. Unnecessary

* Why?

11) Which of the following teacher/student classroom interaction patterns is recommended? Why? (You may choose more than one answer)
a. Greeting
b. Farewell
c. Small talk
d. Nothing at all

* Why? 